\title{
Synthesis, Spectral and Thermal Studies on Schiff Base Derivatives of Heterobimetallic [Ca(II)-Ti(IV)]- $\mu$-oxoisopropoxide
}

\author{
JAI DEVI $^{\mathrm{a}}$ and RAJESH KUMAR* \\ ${ }^{a}$ Department of Chemistry, Sri Venkateswara University, \\ Gajraula, J.P. Nagar, Uttar Pradesh, India \\ Department of Chemistry, HCTM Technical Campus, Kaithal-136027, India \\ dhullrajesh79@gmail.com
}

Received 22 March 2013 / Accepted 30 April 2013

\begin{abstract}
New Schiff base derivatives of heterobimetallic- $\mu$-oxoisopropoxide $\left[\mathrm{CaO}_{2} \mathrm{Ti}_{2}\left(\mathrm{OPr}^{\mathrm{i}}\right)_{6}\right]$ have been synthesized by thermal condensation of $\mu$-oxoisopropoxide with salicylidene-aniline $\left(\mathrm{HSB}^{1}\right)$, salicylidene- $o$-toluidene $\left(\mathrm{HSB}^{2}\right)$ and salicylidene- $p$-chloroaniline $\left(\mathrm{HSB}^{3}\right)$ in different molar ratios (1:1-1:4) yielded the compounds of the type $\left[\mathrm{CaO}_{2} \mathrm{Ti}_{2}\left(\mathrm{OPr}^{\mathrm{i}}\right)_{6-\mathrm{n}}(\mathrm{SB})_{\mathrm{n}}\right]$ (where $\mathrm{n}$ is $1-4$ and $\mathrm{SB}$ $=$ Schiff base anion) respectively. The Schiff base derivatives have been characterized by elemental, spectral (IR, ${ }^{1} \mathrm{H},{ }^{13} \mathrm{C} \mathrm{NMR}$ ), thermal and molecular weight measurement. Hydrothermally assisted sol-gel process gives the hydrolyzed product and thermal study of these products favors the formation of multicomponent oxides. The studies reveal that Schiff base derivatives are monomeric in nature and low susceptible to hydrolysis as compared to parent compound and may prove excellent precursors for the mixed metal oxides.
\end{abstract}

Keywords: Heterobimetallic- $\mu$-oxoisopropoxide, Calcium, Titanium, Schiff base, Thermoanalysis

\section{Introduction}

Nano-structured oxide, the new type of materials shows properties different from materials with $\mu \mathrm{m}$-scale microstructures are gaining more and more interests during the past few years. A variety of chemical routes have been developed to prepare ceramic nano-structures, because the traditional solid-state method could not meet particle size requirements and versatility of synthesis process. Some chemical methods offer possibly a preparation at lower temperatures, a homogenous primary structure and limited higher order aggregation and a small distribution of particle sizes. The investigation and the use of heterometallic alkoxides as single-source molecules precursors for synthesis of oxides have seen a rapid growth during the last more than one and half decade. The bimetallic oxo complexes, the true precursors play a significant role in the phase formation of complex oxides. The M-O-M bridges in bimetallic oxo complexes provide homogeneity of the newly formed oxide phases at the molecular level. The above-considered peculiarity in the composition, stoichiometry, solubility and reactivity of ortho- and oxoalkoxides are widely used in the sol-gel synthesis of a series of very important composites ${ }^{1}$. The uses of heterometallic alkoxides as single-source molecules precursors for synthesis of oxides have seen a rapid growth 
during the last one and half decades. The control of particle size and the morphology of the oxide are of crucial importance nowadays both from the fundamental and industrial point of view ${ }^{2}$. The mixed metal oxides prepared from heterometallic- $\mu$-oxoalkoxides ${ }^{3-6}$ have been used for absorbing harmful chemicals ${ }^{7}$ and gases such as $\mathrm{SO}_{2}, \mathrm{CCl}_{4}$ and decontaminating chemical warfare agents ${ }^{8}$. The alkaline earth metal titanates like barium titanate, calcium titanate $\left(\mathrm{CaTiO}_{3}\right)$, strontium titanate $\left(\mathrm{SrTiO}_{3}\right.$ and $\left.\mathrm{Ba}_{\mathrm{x}} \mathrm{Sr}_{1-\mathrm{x}} \mathrm{TiO}_{3}\right)$ due to their exceptional properties expose potential applications in multilayer ceramic capacitors, electro-optic, dielectric and piezoelectric devices ${ }^{9-12}$. The perovskite $\mathrm{CaTiO}_{3}$ with its unique structure, higher stability and biocompatibility, finds potential application in the fields of communication, electronics and in biotechnology ${ }^{13-15}$. The ability of immobilizing the rare earths of $\mathrm{CaTiO}_{3}$ by forming solid solutions with highly radioactive wastes makes the $\mathrm{CaTiO}_{3}$ useful for disposal of highly radioactive wastes ${ }^{16-17}$. Recently, calcium titanate has also been used as a competent anticorrosion pigment for paints ${ }^{18}$. Apart from their role as precursors for mixed metal oxides, the bimetallic- $\mu$-oxoalkoxides of transition metals have been found to rank among the excellent catalysts for the polymerization of heterocyclic monomers like lactones, oxiranes, thiiranes and epoxides ${ }^{19-20}$.

In the present investigation, the derivatives of heterobimetallic $[\mathrm{Ca}(\mathrm{II})-\mathrm{Ti}(\mathrm{IV})]-\mu$ oxoisopropoxide are prepared from the condensation of $\left[\mathrm{CaO}_{2} \mathrm{Ti}_{2}\left(\mathrm{OPr}^{\mathrm{i}}\right)_{6}\right]$ with different Schiff bases in molar ratios (1:1-1:4) and the reaction proceeds with stepwise formation of Schiff base derivatives of bimetallic [Ca(II)-Ti(IV)]- $\mu$-oxoisopropoxide, which are the molecular species that can be purified by distillation, allowing the isolation of pure molecular precursors.

\section{Experimental}

All the operations were carried out in dry nitrogen atmosphere using a vacuum line. Hydrocarbon solvents and reagents used were purified and dried by standard methods. The general technique and physical measurement were carried out as described elsewhere ${ }^{21-26}$. Hydrated calcium acetate (Aldrich) was made anhydrous with acetic anhydride and titanium isopropoxide $\left[\operatorname{Ti}^{i}\left(\mathrm{OPr}^{\mathrm{i}}\right)_{4}\right]$ (Aldrich) used without further purification. The salicylidene-aniline $\left(\mathrm{HSB}^{1}\right)$, salicylidene- $o$ toluidene $\left(\mathrm{HSB}^{2}\right)$ and salicylidene-p-chloroaniline $\left(\mathrm{HSB}^{3}\right)$ were prepared in laboratory and purified before use. The isopropoxy groups in the $\mu$-oxoisopropoxide and liberated isopropanol formed in preparation of Schiff base derivatives were estimated oxidimetrically. Calcium was determined complexometrically and gravimetric estimation has been done for titanium ${ }^{25}$. Titanium was estimated as $\mathrm{TiO}_{2}$ via the formation of titanium-phenazone complex ${ }^{25}$. PerkinElmer 1710 FTIR spectrometer over the range $4000-400 \mathrm{~cm}^{-1}$ used to record the Infrared spectra. The ${ }^{1} \mathrm{H},{ }^{13} \mathrm{C}$ NMR spectra were recorded in $\mathrm{CDCl}_{3}$ on Bruker Avance II $400 \mathrm{NMR}$ spectrometer. TG study has been made on Diamond TG/DTA PerkinElmer instrument. Elemental analyses were carried out by PerkinElmer 2400 II series CHNS/O Analyzer.

\section{Synthesis of derivatives of $\left[\mathrm{CaO}_{2} \mathrm{Ti}_{2}\left(\mathrm{OPr}^{i}\right)_{6}\right]$ with Schiff bases}

The $[\mathrm{Ca}(\mathrm{II})$-Ti(IV)]- $\mu$-oxoisopropoxide was synthesized by reported methods on thermal condensation of $\mathrm{Ca}(\mathrm{OAc})_{2}$ and $\mathrm{Ti}\left(\mathrm{OPr}^{\mathrm{i}}\right)_{4}$ in mixture of xylene and decalin in 1:2 molar ratio ${ }^{21-24}$.

\section{Reaction of $\mu$-oxo compound with salicylidene-aniline in 1:1 molar ratio}

The $\left[\mathrm{CaO}_{2} \mathrm{Ti}_{2}\left(\mathrm{OPr}^{\mathrm{i}}\right)_{6}\right](0.435 \mathrm{~g}, 0.837 \mathrm{mmol})$ and salicylidene-aniline $(0.165 \mathrm{~g}, 0.837 \mathrm{mmol})$ were refluxed in benzene were refluxed in $\sim 50 \mathrm{~mL}$ benzene in a flask connected to a short distillation column on an oil bath for about $7 \mathrm{~h}$. The isopropanol liberated at $72-78^{\circ} \mathrm{C}$ was fractionated as the binary azeotrope of isoproponol-benzene. The azeotrope was collected and checked for completion of the reaction. The excess of the solvent was then removed under reduced pressure yielding a yellowish semi-solid product. The syntheses of other schiff base derivatives were carried out by similar procedure and the analytical results have been summarized in Table 1 . 
Table 1. Analytical and physical data of studied compounds

\begin{tabular}{|c|c|c|c|c|c|c|c|c|c|c|}
\hline \multirow[t]{2}{*}{ S.No. } & \multirow{2}{*}{$\begin{array}{l}\text { Compound g, } \\
\text { mmol }\end{array}$} & \multirow{2}{*}{$\begin{array}{l}\text { Ligand } \\
\text { g, mmol }\end{array}$} & \multirow{2}{*}{$\begin{array}{c}\text { Refluxing } \\
\text { time h }\end{array}$} & \multirow[t]{2}{*}{ Product, $\%$} & \multicolumn{6}{|c|}{ Anal. Found (Calcd.) } \\
\hline & & & & & $\mathrm{OPr}^{\mathrm{i}} \mathrm{g}$ & $\mathrm{Ca} \%$ & $\mathrm{Ti} \%$ & $\mathrm{C} \%$ & $\mathrm{H} \%$ & $\mathrm{~N} \%$ \\
\hline \multirow[t]{2}{*}{1} & {$\left[\mathrm{CaO}_{2} \mathrm{Ti}_{2}\left(\mathrm{OPr}^{\mathrm{i}}\right)_{6}\right]$} & $\mathrm{HSB}^{1}$ & \multirow[t]{2}{*}{7} & {$\left[\mathrm{CaO}_{2} \mathrm{Ti}_{2}\left(\mathrm{OPr}^{\mathrm{i}}\right)_{5}\right.$} & 0.03 & 6.48 & 14.28 & 50.69 & 6.31 & 2.11 \\
\hline & $0.435(0.837)$ & $0.165(0.837)$ & & $\left.\left(\mathrm{SB}^{1}\right)\right] 78.9$ & $(0.03)$ & $(6.08)$ & $(14.30)$ & $(51.14)$ & $(6.84)$ & (2.13) \\
\hline \multirow[t]{2}{*}{2} & {$\left[\mathrm{CaO}_{2} \mathrm{Ti}_{2}\left(\mathrm{OPr}^{\mathrm{i}}\right)_{6}\right]$} & $\mathrm{HSB}^{1}$ & \multirow[t]{2}{*}{$81 / 2$} & {$\left[\mathrm{CaO}_{2} \mathrm{Ti}_{2}\left(\mathrm{OPr}^{\mathrm{i}}\right)_{4}\right.$} & 0.06 & 4.97 & 11.52 & 56.38 & 5.97 & 3.54 \\
\hline & $0.364(0.7)$ & $0.276(1.401)$ & & $\left.\left(\mathrm{SB}^{1}\right)_{2}\right] 75.3$ & $(0.06)$ & $(5.03)$ & $(11.83)$ & $(57.43)$ & $(6.04)$ & $(3.52)$ \\
\hline \multirow[t]{2}{*}{3} & {$\left[\mathrm{CaO}_{2} \mathrm{Ti}_{2}\left(\mathrm{OPr}^{\mathrm{i}}\right)_{6}\right]$} & $\mathrm{HSB}^{1}$ & \multirow[t]{2}{*}{9} & {$\left[\mathrm{CaO}_{2} \mathrm{Ti}_{2}\left(\mathrm{OPr}^{\mathrm{i}}\right)_{3}\right.$} & 0.09 & 4.28 & 9.87 & 62.37 & 5.12 & 4.56 \\
\hline & $0.286(0.551)$ & $0.326(1.654)$ & & $\left.\left(\mathrm{SB}^{1}\right)_{3}\right] 80.5$ & $(0.09)$ & $(4.29)$ & $(10.09)$ & $(61.86)$ & $(5.47)$ & $(4.51)$ \\
\hline \multirow[t]{2}{*}{4} & {$\left[\mathrm{CaO}_{2} \mathrm{Ti}_{2}\left(\mathrm{OPr}^{\mathrm{i}}\right)_{6}\right]$} & $\mathrm{HSB}^{1}$ & \multirow[t]{2}{*}{12} & {$\left[\mathrm{CaO}_{2} \mathrm{Ti}_{2}\left(\mathrm{OPr}^{\mathrm{i}}\right)_{2}\right.$} & 0.11 & 3.87 & 8.68 & 64.86 & 5.5 & 5.32 \\
\hline & $0.257(0.496)$ & $0.391(1.984)$ & & $\left.\left(\mathrm{SB}^{1}\right)_{4}\right] 79.3$ & $(0.12)$ & $(3.74)$ & $(8.80)$ & $(65.15)$ & $(5.05)$ & $(5.24)$ \\
\hline \multirow[t]{2}{*}{5} & {$\left[\mathrm{CaO}_{2} \mathrm{Ti}_{2}\left(\mathrm{OPr}^{\mathrm{i}}\right)_{6}\right]$} & $\mathrm{HSB}^{2}$ & \multirow[t]{2}{*}{7} & {$\left[\mathrm{CaO}_{2} \mathrm{Ti}_{2}\left(\mathrm{OPr}^{\mathrm{i}}\right)_{5}\right.$} & 0.03 & 5.74 & 12.99 & 48.98 & 6.54 & 2.09 \\
\hline & $0.421(0.811)$ & $0.185(0.811)$ & & $\left.\left(\mathrm{SB}^{2}\right)\right] 81.6$ & $(0.03)$ & $(5.81)$ & $(13.66)$ & $(50.58)$ & $(6.83)$ & $(2.03)$ \\
\hline \multirow[t]{2}{*}{6} & {$\left[\mathrm{CaO}_{2} \mathrm{Ti}_{2}\left(\mathrm{OPr}^{\mathrm{i}}\right)_{6}\right]$} & $\mathrm{HSB}^{2}$ & \multirow[t]{2}{*}{9} & {$\left[\mathrm{CaO}_{2} \mathrm{Ti}_{2}\left(\mathrm{OPr}^{\mathrm{i}}\right)_{4}\right.$} & 0.06 & 4.36 & 10.79 & 55.68 & 6.24 & 3.14 \\
\hline & $0.281(0.541)$ & $0.247(1.083)$ & & $\left.\left(\mathrm{SB}^{2}\right)_{2}\right] 80.5$ & $(0.06)$ & $(4.67)$ & $(10.98)$ & $(56.07)$ & (6.07) & $(3.27)$ \\
\hline \multirow[t]{2}{*}{7} & {$\left[\mathrm{CaO}_{2} \mathrm{Ti}_{2}\left(\mathrm{OPr}^{\mathrm{i}}\right)_{6}\right]$} & $\mathrm{HSB}^{2}$ & \multirow[t]{2}{*}{$101 / 2$} & {$\left[\mathrm{CaO}_{2} \mathrm{Ti}_{2}\left(\mathrm{OPr}^{\mathrm{i}}\right)_{3}(\mathrm{~S}\right.$} & 0.09 & 3.58 & 9.38 & 60.71 & 5.52 & 3.87 \\
\hline & $0.242(0.466)$ & $0.319(1.399)$ & & $\left.\left.\mathrm{B}^{2}\right)_{3}\right] 78.6$ & $(0.09)$ & $(3.90)$ & (9.17) & $(59.76)$ & $(5.56)$ & $(4.1)$ \\
\hline \multirow[t]{2}{*}{8} & {$\left[\mathrm{CaO}_{2} \mathrm{Ti}_{2}\left(\mathrm{OPr}^{\mathrm{i}}\right)_{6}\right]$} & $\mathrm{HSB}^{2}$ & \multirow[t]{2}{*}{12} & {$\left[\mathrm{CaO}_{2} \mathrm{Ti}_{2}\left(\mathrm{OPr}^{\mathrm{i}}\right)_{4}\right.$} & 0.11 & 3.21 & 7.51 & 61.74 & 5.32 & 4.52 \\
\hline & $0.219(0.423)$ & $0.386(1.692)$ & & $\left.\left(\mathrm{SB}^{2}\right)_{4}\right] 80.4$ & $(0.12)$ & $(3.35)$ & (7.88) & $(62.41)$ & $(5.20)$ & (4.69) \\
\hline \multirow[t]{2}{*}{9} & {$\left[\mathrm{CaO}_{2} \mathrm{Ti}_{2}\left(\mathrm{OPr}^{\mathrm{i}}\right)_{6}\right]$} & $\mathrm{HSB}^{3}$ & \multirow[t]{2}{*}{7} & {$\left[\mathrm{CaO}_{2} \mathrm{Ti}_{2}\left(\mathrm{OPr}^{\mathrm{i}}\right)_{5}(\mathrm{~S}\right.$} & 0.03 & 5.80 & 13.75 & 47.32 & 6.32 & 2.01 \\
\hline & $0.327(0.629)$ & $0.146(0.629)$ & & $\left.\left.\mathrm{B}^{3}\right)\right] 81.3$ & $(0.03)$ & $(5.78)$ & $(13.58)$ & $(48.55)$ & $(6.35)$ & $(2.02)$ \\
\hline \multirow[t]{2}{*}{10} & {$\left[\mathrm{CaO}_{2} \mathrm{Ti}_{2}\left(\mathrm{OPr}^{\mathrm{i}}\right)_{6}\right]$} & $\mathrm{HSB}^{3}$ & \multirow[t]{2}{*}{$81 / 2$} & {$\left[\mathrm{CaO}_{2} \mathrm{Ti}_{2}\left(\mathrm{OPr}^{\mathrm{i}}\right)_{4}(\mathrm{~S}\right.$} & 0.06 & 4.60 & 10.52 & 53.64 & 5.54 & 3.33 \\
\hline & $0.271(0.523)$ & $0.243(1.047)$ & & $\left.\left.\mathrm{B}^{3}\right)_{2}\right] 81.9$ & $(0.06)$ & $(4.62)$ & $(10.87)$ & $(52.77)$ & $(5.43)$ & $(3.24)$ \\
\hline \multirow[t]{2}{*}{11} & $\left.\mathrm{CaO}_{2} \mathrm{Ti}_{2}\left(\mathrm{OPr}^{\mathrm{i}}\right)_{6}\right]$ & $\mathrm{HSB}^{3}$ & \multirow[t]{2}{*}{$101 / 2$} & {$\left[\mathrm{CaO}_{2} \mathrm{Ti}_{2}\left(\mathrm{OPr}^{\mathrm{i}}\right)_{3}(\mathrm{~S}\right.$} & 0.08 & 3.75 & 9.05 & 54.69 & 4.66 & 4.01 \\
\hline & $0.236(0.455)$ & $0.317(1.366)$ & & $\left.\left.\mathrm{B}^{3}\right)_{3}\right] 81.5$ & $(0.09)$ & $(3.86)$ & $(9.07)$ & $(55.59)$ & $(4.82)$ & $(4.05)$ \\
\hline \multirow[t]{2}{*}{12} & {$\left[\mathrm{CaO}_{2} \mathrm{Ti}_{2}\left(\mathrm{OPr}^{\mathrm{i}}\right)_{6}\right]$} & $\mathrm{HSB}^{3}$ & \multirow[t]{2}{*}{12} & {$\left[\mathrm{CaO}_{2} \mathrm{Ti}_{2}\left(\mathrm{OPr}^{\mathrm{i}}\right)_{2}(\mathrm{~S}\right.$} & 0.11 & 3.32 & 7.65 & 57.36 & 4.25 & 4.47 \\
\hline & $0.221(0.425)$ & $0.397(1.702)$ & & $\left.\left.\mathrm{B}^{3}\right)_{4}\right] 78.9$ & $(0.12)$ & $(3.31)$ & $(7.78)$ & $(57.61)$ & $(4.38)$ & $(4.63)$ \\
\hline
\end{tabular}


The hydrolyzed product of Schiff bases of $\mu$-oxo compound obtained by hydrothermally assisted sol-gel processing. For the hydrothermally assisted sol-gel processing, Schiff base derivatives were diluted 20 times by weight with isopropanol, the mixture was loaded into a glass container and transferred into a $300 \mathrm{~mL}$ stainless steel autoclave. Dilution of Schiff base derivatives and their transfer into autoclave was performed in moisture-free atmosphere to prevent their hydrolysis before introducing into a hydrothermal chamber. The gap between glass container and chamber was filled with $40 \mathrm{~mL}$ of distilled water and then the autoclave was tightly closed. The chamber was heated $120{ }^{\circ} \mathrm{C}$ for five hours, the autoclave was cooled and the product was filtered off and dried overnight at $100{ }^{\circ} \mathrm{C}$.

\section{Results and Discussion}

To overcome the phase segregation problem and provide a excellent precursors for bicomponent oxides, many reactions of $[\mathrm{Ca}(\mathrm{II})-\mathrm{Ti}(\mathrm{IV})]-\mu$-oxoisopropoxide with bidentate Schiff bases (HSB) i.e. salicylidene aniline $\left(\mathrm{HSB}^{1}\right)$, salicylidene-o-toluidene $\left(\mathrm{HSB}^{2}\right)$, salicylidene $p$-chloroaniline $\left(\mathrm{HSB}^{3}\right)$ were performed in different molar ratios in refluxing benzene, yielding the products of type $\left[\mathrm{CaO}_{2} \mathrm{Ti}_{2}\left(\mathrm{OPr}^{\mathrm{i}}\right)_{5}(\mathrm{SB})\right], \quad\left[\mathrm{CaO}_{2} \mathrm{Ti}_{2}\left(\mathrm{OPr}^{\mathrm{i}}\right)_{4}(\mathrm{SB})_{2}\right]$, $\left[\mathrm{CaO}_{2} \mathrm{Ti}_{2}\left(\mathrm{OPr}^{\mathrm{i}}\right)_{3}(\mathrm{SB})_{3}\right]$ and $\left[\mathrm{CaO}_{2} \mathrm{Ti}_{2}\left(\mathrm{OPr}^{\mathrm{i}}\right)_{2}(\mathrm{SB})_{4}\right]$. The preparation of the Schiff base derivatives of $\left[\mathrm{CaO}_{2} \mathrm{Ti}_{2}\left(\mathrm{OPr}^{\mathrm{i}}\right)_{6}\right]$ follows the following reaction Scheme 1.

$$
\begin{aligned}
& {\left[\mathrm{CaO}_{2} \mathrm{Ti}_{2}\left(\mathrm{OPr}^{\mathrm{i}}\right)_{6}\right]+\mathrm{nHSB} \text { refluxing benzene }\left[\mathrm{CaO}_{2} \mathrm{Ti}_{2}\left(\mathrm{OPr}^{\mathrm{i}}\right)_{6-\mathrm{n}}(\mathrm{SB})_{\mathrm{n}}\right]+\mathrm{nPr} \operatorname{Pr}^{\mathrm{i} O H}} \\
& (n=1-4, \text { HSB }=\text { Schiff bases })
\end{aligned}
$$

\section{Scheme 1}

The $\left[\mathrm{CaO}_{2} \mathrm{Ti}_{2}\left(\mathrm{OPr}^{\mathrm{i}}\right)_{6}\right]$ and its Schiff base derivatives are susceptible to hydrolysis and soluble in common organic solvents such as benzene, chloroform and carbon tetrachloride etc. The isopropanol liberated during the course of the reaction was collected azeotropically (isopropanol-benzene) and estimated oxidimetrically to check the progress of the reaction. It was observed that only four out of the six isopropoxy groups of [Ca(II)-Ti(IV)]- $\mu$ oxoisopropoxide could be replaced by Schiff bases. Further replacement of isopropoxy groups could not be achieved even with an excess of ligand (Schiff bases) and prolonged refluxing time $(28 \mathrm{~h})$. This indicates the non-replacement of bridging isopropoxy groups and that only terminal isopropoxy groups are substituted by Schiff bases.

\section{Spectral Analysis of Schiff base derivatives of $\left[\mathrm{CaO}_{2} \mathrm{Ti}_{2}\left(\mathrm{OPr}^{\mathrm{i}}\right)_{6}\right]$}

\section{IR spectra}

The IR spectra of the 1:3 Schiff base derivatives of $\left[\mathrm{CaO}_{2} \mathrm{Ti}_{2}\left(\mathrm{OPr}^{\mathrm{i}}\right)_{6}\right]$ show absorption bands in the region $1360-1340 \mathrm{~cm}^{-1}$ and $1165-1150 \mathrm{~cm}^{-1}$ are the characterstics of gem-dimethyl portion and combination band $v\left(\mathrm{C}-\mathrm{O}+\mathrm{OPr}^{\mathrm{i}}\right)$ of the terminal and bridging isopropoxy group respectively ${ }^{30}$. No peak is observed at $1165 \mathrm{~cm}^{-1}$ in the spectrum of 1:4 Schiff base derivatives indicates the absence of terminal isopropoxy group. A band appeared at approximately $950 \mathrm{~cm}^{-1}$ is due to $v(\mathrm{C}-\mathrm{O})$ stretching of bridging isopropoxy group. Similar spectra obtained for compounds formed by reactions of 1:5 and 1:6 molar ratios of $\mu$-oxo compound and Schiff bases as of 1:4 Schiff base derivatives of $\mu$-oxoisopropoxide. This reavels the non-replacement of bridging isopropoxy groups by Schiff bases.

The $v(\mathrm{O}-\mathrm{H})$ band occurring in the region $~ 3400-3100 \mathrm{~cm}^{-1}$ in the Schiff bases disappears completely in the derivatives, indicating the deprotonation of these ligands. Schiff bases show intense bands at $\sim 1565 \mathrm{~cm}^{-1}$ and $\sim 1260 \mathrm{~cm}^{-1}$ due to $\mathrm{v}(\mathrm{C}=\mathrm{N})$ and $\mathrm{v}(\mathrm{C}-\mathrm{O})$ vibrations of azomethine and phenolic groups respectively. The downward shift in $v(\mathrm{C}=\mathrm{N})$ stretch by $\sim 15$ $25 \mathrm{~cm}^{-1}$ indicating the coordination of azomethine nitrogen of the ligand to the metal 
atom and upward shift in $v(\mathrm{C}-\mathrm{O})$ by $\sim 20-30 \mathrm{~cm}^{-1}$ suggesting the bond formation of phenolic oxygen of the Schiff base to the metal in the derivatives ${ }^{27}$. A number of peaks are observed in the region 700-400 $\mathrm{cm}^{-1}$ due to $\mathrm{M}-\mathrm{O}$ and $\mathrm{M}-\mathrm{N}$ stretching vibrations in $\mu$-oxo compounds which is difficult to assign exactly due to the overlapping of bands in this region ${ }^{28}$. A number of peaks are observed in the region $700-400 \mathrm{~cm}^{-1}$ due to $\mathrm{M}-\mathrm{O}$ and $\mathrm{M}-\mathrm{N}$ stretching vibrations in $\mu$-oxo compounds which is difficult to assign exactly due to the overlapping of bands in this region $^{29}$.

\section{NMR spectra}

${ }^{1} \mathrm{H}$ NMR spectra of all the Schiff base derivatives of $\left[\mathrm{CaO}_{2} \mathrm{Ti}_{2}\left(\mathrm{OPr}^{\mathrm{i}}\right)_{6}\right]$ show broad multiplet centered between $\delta$ 0.8-1.2 ppm due to the intermixing of methyl protons of isopropoxy groups. A broad multiplet centered at $\delta 4.1$ is due to the methine proton of isopropoxy groups in the spectra of all derivatives. Very similar spectra obtained for compounds formed by reactions of 1:5 and 1:6 molar ratios of $\mu$-oxo compound and Schiff bases as of 1:4 Schiff base derivatives of $\mu$-oxoisopropoxide. This confirms the non-replacement of bridging isopropoxy groups by Schiff bases.

In the ${ }^{1} \mathrm{H}$ NMR spectra of all derivatives, the signals observed at $\delta 6.8-7.8 \mathrm{ppm}$ are due to phenyl ring protons. Disappearance of peak at $\delta 11.2 \mathrm{ppm}$ due to phenolic $(\mathrm{O}-\mathrm{H})$ protons of Schiff base in their derivatives of $\left[\mathrm{CaO}_{2} \mathrm{Ti}_{2}\left(\mathrm{OPr}^{\mathrm{i}}\right)_{6}\right]$ indicates the deprotonation of phenolic group. In the case of salicylidene-o-toluidene derivatives an additional signal at $\delta$ 2.3-2.5 ppm has been observed due to methyl protons substituted on the benzene ring.

The ${ }^{13} \mathrm{C}$ NMR spectra mono derivatives of $\left[\mathrm{CaO}_{2} \mathrm{Ti}_{2}\left(\mathrm{OPr}^{\mathrm{i}}\right)_{6}\right]$ shows two prominent peaks at $\delta \sim 26.3$ and $\delta \sim 28.2 \mathrm{ppm}$ assignable to the methyl carbon of terminal and interamolecularly bridged isopropoxy moiety and two different type of methine carbons of isopropoxy group is confirmed by the two signals observed at $\delta \sim 62.6 \mathrm{ppm}$ and $\delta \sim 63.7 \mathrm{ppm}^{30}$. The spectra of $1: 4$ Schiff base derivatives of $\mu$-oxoisopropoxide show the absence of terminal isopropoxy group. Very similar spectra obtained for compounds formed by reactions of 1:5 and 1:6 molar ratios of $\mu$-oxo compound and Schiff bases as of 1:4 Schiff base derivatives of $\mu$-oxoisopropoxide. This confirms the non-replacement of bridging isopropoxy groups by Schiff bases.

Two signals observed in the range $\delta 160.1-164.7 \mathrm{ppm}$ and $\delta 150.8-147.3 \mathrm{ppm}$ are due to carbonyl carbon and methine carbon attached to nitrogen of ligand moiety in all the Schiff derivatives of $\mu$-oxoisopropoxide compound. Morever, a number of signals are observed between $\delta 133.5-117.8 \mathrm{ppm}$ due to the different carbons of two phenyl rings ${ }^{30}$.

\section{Thermal studies}

The thermal decomposition of Schiff base derivatives of $\left[\mathrm{CaO}_{2} \mathrm{Ti}\left(\mathrm{OPr}^{\mathrm{i}}\right)_{4}\right]$ have been examined by thermogravimetric analysis under a flow of dry nitrogen, up to $800{ }^{\circ} \mathrm{C}$ at a heating rate of $10^{\circ} \mathrm{C} / \mathrm{min}$. The minor weight loss (1.32-1.48\%) starts at $57.5-59.3{ }^{\circ} \mathrm{C}$ and completed at $185-187^{\circ} \mathrm{C}$ with a weight loss of due to presence of moisture and fraction of solvent present, if any. The second and major one starts at $180-185^{\circ} \mathrm{C}$ and is completed at $359-363{ }^{\circ} \mathrm{C}$, resulting in a residue amounting to $11.245-12.583 \%$ of the initial weight, probably due to the decomposition of partially hydrolyzed $\mu$-oxo Schiff base into metal/mixed metal oxides suggesting the volatile nature of compound ${ }^{31}$.

The thermogravimetric analysis of various hydrolyzed product of different Schiff base derivatives have been performed up to $800{ }^{\circ} \mathrm{C}$ at $10{ }^{\circ} \mathrm{C} / \mathrm{min}$. Thermograms of various hydrolysed Schiff base derivatives studied as, the weight loss in stage (a) observed due to the traces of water and solvent present in hydrolyzed product of $\mu$-oxo compound. The major weight loss in stage (b) occurs probably due to the elimination of hydroxy groups and organic moieties present in the hydrolyzed product which is directly followed by last stage 
(c) ranging from $345-359{ }^{\circ} \mathrm{C}$ to $800{ }^{\circ} \mathrm{C}$, leaving a residue that is less than the calculated for mixed metal oxide and metal oxides $\left(\mathrm{CaTiO}_{3}\right.$ and $\left.\mathrm{TiO}_{2}\right)$. The detailed study of thermograms of hydrolyzed product of various Schiff base derivatives is summarized in Table 2. The molecular weight measurement carried out in dry benzene using cryoscopic method suggests monomeric nature of Schiff base derivatives.

Table 2. Study of thermograms of hydrolyzed product of various Schiff base derivatives of $\left[\mathrm{CaO}_{2} \mathrm{Ti}\left(\mathrm{OPr}^{\mathrm{i}}\right)_{4}\right]$

\begin{tabular}{|c|c|c|c|}
\hline S. No & Compound & Temperature range, ${ }^{\circ} \mathrm{C}$ & Weight loss, $\%$ \\
\hline 1. & {$\left[\mathrm{CaO}_{2} \mathrm{Ti}_{2}\left(\mathrm{OPr}^{\mathrm{i}}\right)_{5}\left(\mathrm{SB}^{1}\right)\right]$} & $\begin{array}{l}\text { (a) } 55-220 \text { (b) } 220-345 \\
\text { (c) }>345\end{array}$ & $\begin{array}{l}\text { (a) } 5 \text { (b) } 50.52 \\
\text { (c) No significant loss }\end{array}$ \\
\hline 2. & {$\left[\mathrm{CaO}_{2} \mathrm{Ti}_{2}\left(\mathrm{OPr}^{\mathrm{i}}\right)_{4}\left(\mathrm{SB}^{1}\right)_{2}\right]$} & $\begin{array}{l}\text { (a) } 54-222 \text { (b) } 222-349 \\
\text { (c) }>349\end{array}$ & $\begin{array}{l}\text { (a) } 6 \text { (b) } 61.87 \\
\text { (c) No significant loss }\end{array}$ \\
\hline 3. & {$\left[\mathrm{CaO}_{2} \mathrm{Ti}_{2}\left(\mathrm{OPr}^{\mathrm{i}}\right)_{3}\left(\mathrm{SB}^{2}\right)_{3}\right]$} & $\begin{array}{l}\text { (a) } 58-219 \text { (b) } 219-352 \\
\text { (c) }>352\end{array}$ & $\begin{array}{l}\text { (a) } 6 \text { (b) } 68.54 \\
\text { (c) No Significant loss }\end{array}$ \\
\hline 4. & {$\left[\mathrm{CaO}_{2} \mathrm{Ti}_{2}\left(\mathrm{OPr}^{\mathrm{i}}\right)_{2}\left(\mathrm{SB}^{2}\right)_{4}\right]$} & $\begin{array}{l}\text { (a) } 56-221 \text { (b) } 221-355 \\
\text { (c) }>355\end{array}$ & $\begin{array}{l}\text { (a) } 4 \text { (b) } 75.63 \\
\text { (c) No significant loss }\end{array}$ \\
\hline 5. & {$\left[\mathrm{CaO}_{2} \mathrm{Ti}_{2}\left(\mathrm{OPr}^{\mathrm{i}}\right)_{5}\left(\mathrm{SB}^{3}\right)\right]$} & $\begin{array}{l}\text { (a) } 57-220 \text { (b) } 220-348 \\
\text { (c) }>348\end{array}$ & $\begin{array}{l}\text { (a) } 4 \text { (b) } 54.19 \\
\text { (c) No significant loss }\end{array}$ \\
\hline 6. & {$\left[\mathrm{CaO}_{2} \mathrm{Ti}_{2}\left(\mathrm{OPr}^{\mathrm{i}}\right)_{4}\left(\mathrm{SB}^{3}\right)_{2}\right]$} & $\begin{array}{l}\text { (a) } 59-225 \text { (b) } 225-355 \\
\text { (c) }>355\end{array}$ & $\begin{array}{l}\text { (a) } 5 \text { (b) } 62.85 \\
\text { (c) No significant loss }\end{array}$ \\
\hline 7. & {$\left[\mathrm{CaO}_{2} \mathrm{Ti}_{2}\left(\mathrm{OPr}^{\mathrm{i}}\right)_{3}\left(\mathrm{SB}^{4}\right)_{3}\right]$} & $\begin{array}{l}\text { (a) } 56-224 \text { (b) } 224-350 \\
\text { (c) }>350\end{array}$ & $\begin{array}{l}\text { (a) } 5 \text { (b) } 73.29 \\
\text { (c) No significant loss }\end{array}$ \\
\hline 8. & {$\left[\mathrm{CaO}_{2} \mathrm{Ti}_{2}\left(\mathrm{OPr}^{\mathrm{i}}\right)_{2}\left(\mathrm{SB}^{4}\right)_{4}\right]$} & $\begin{array}{l}\text { (a) } 61-230 \text { (b) } 230-355 \\
\text { (c) }>355\end{array}$ & $\begin{array}{l}\text { (a) } 4 \text { (b) } 76.31 \text {. } \\
\text { (c) No significant loss }\end{array}$ \\
\hline 9. & {$\left[\mathrm{CaO}_{2} \mathrm{Ti}_{2}\left(\mathrm{OPr}^{\mathrm{i}}\right)_{5}\left(\mathrm{SB}^{1}\right)\right]$} & $\begin{array}{l}\text { (a) } 53-224 \text { (b) } 224-348 \\
\text { (c) }>348\end{array}$ & $\begin{array}{l}\text { (a) } 5 \text { (b) } 54.33 \\
\text { (c) No significant loss }\end{array}$ \\
\hline 10. & {$\left[\mathrm{CaO}_{2} \mathrm{Ti}_{2}\left(\mathrm{OPr}^{\mathrm{i}}\right)_{4}\left(\mathrm{SB}^{1}\right)_{2}\right]$} & $\begin{array}{l}\text { (a) } 54-223 \text { (b) } 223-351 \\
\text { (c) }>351\end{array}$ & $\begin{array}{l}\text { (a) } 6 \text { (b) } 64.54 \\
\text { (c) No significant loss }\end{array}$ \\
\hline 11. & {$\left[\mathrm{CaO}_{2} \mathrm{Ti}_{2}\left(\mathrm{OPr}^{\mathrm{i}}\right)_{3}\left(\mathrm{SB}^{2}\right)_{3}\right]$} & $\begin{array}{l}\text { (a) } 58-221 \text { (b) } 221-356 \\
\text { (c) }>356\end{array}$ & $\begin{array}{l}\text { (a) } 6 \text { (b) } 70.48 \\
\text { (c) No Significant loss }\end{array}$ \\
\hline 12. & {$\left[\mathrm{CaO}_{2} \mathrm{Ti}_{2}\left(\mathrm{OPr}^{\mathrm{i}}\right)_{4}\left(\mathrm{SB}^{2}\right)_{2}\right]$} & $\begin{array}{l}\text { (a) } 57-224 \text { (b) 224-359 } \\
\text { (c) }>359\end{array}$ & $\begin{array}{l}\text { (a) } 4 \text { (b) } 77.08 \\
\text { (c) No significant loss }\end{array}$ \\
\hline
\end{tabular}

\section{Conclusion}

The aforementioned studies reveals the suggestive structures of Schiff base derivatives of oxo complex of the type $\left[\mathrm{CaO}_{2} \mathrm{Ti}_{2}\left(\mathrm{OPr}^{\mathrm{i}}\right)_{5}(\mathrm{SB})\right],\left[\mathrm{CaO}_{2} \mathrm{Ti}_{2}\left(\mathrm{OPr}^{\mathrm{i}}\right)_{4}(\mathrm{SB})_{2}\right],\left[\mathrm{CaO}_{2} \mathrm{Ti}_{2}\left(\mathrm{OPr}^{\mathrm{i}}\right)_{3}\right.$ $\left.(\mathrm{SB})_{3}\right]$ and $\left[\mathrm{CaO}_{2} \mathrm{Ti}_{2}\left(\mathrm{OPr}^{\mathrm{i}}\right)_{2}(\mathrm{SB})_{4}\right]$. TGA study reveals the volatile nature of derivatives and their hydrolysed product may fabricate the mixed metal oxides. The proposed structures double and terta derivatives are given in Figure 1 and 2 respectively.

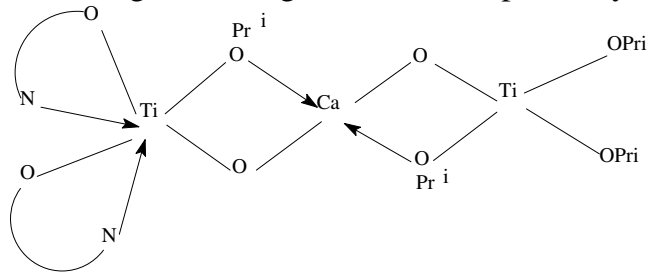

Figure 1. Suggested structure of $\left[\mathrm{CaO}_{2} \mathrm{Ti}_{2}\left(\mathrm{OPr}^{\mathrm{i}}\right)_{4}(\mathrm{SB})_{2}\right]$ 


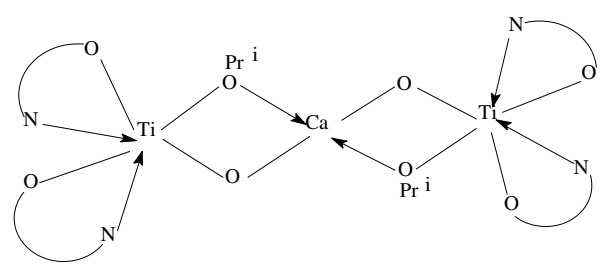

Figure 2. Suggested structure of $\left[\mathrm{CaO}_{2} \mathrm{Ti}_{2}\left(\mathrm{OPr}^{\mathrm{i}}\right)_{2}(\mathrm{SB})_{4}\right]$

\section{Acknowledgement}

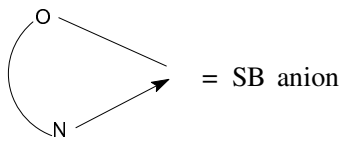

Sincere thanks are due to Haryana College of Technology and Management Technical Campus, Kaithal for providing the necessary facilities to the author.

\section{References}

1. Turova N Ya, Russian Chem Rev., 2004, 73(11), 1041-1064.

2. Vayssieres L, Hagfeldt A and Lindquist S E, Pure Appl Chem., 2000, 72, 47-52.

3. Kapoor P N, Bhagi A K, Mulukutla R S and Klabunde K, J Dekker Encyclopedia of Nanoscience and Nanotechnology; Marcel Deker: New York, 2004, 2007.

4. Kapoor P N, Sharma H K, Bhagi A K and Sharma M, J Indian Chem Soc., 2004, 81, 273-281.

5. Mohammadnezhad G, Amini M M and Khavasi H R, Dalton Trans., 2010, 39, 10830-10832.

6. Hubert-Pfalzgraf L G and Daniele S C R, Chimie, 2004, 7, 521-527.

7. Carnes C L, Kapoor P N, Klabunde K J and Bonevich J, Chem Mater., 2002, 14, 2922-2929.

8. Wagner G W, Procell L R, O'Connor R J, Munavalli S, Carnes C L, Kapoor P N, Klabunde K J, J Am Chem Soc., 2001, 123, 1636-1644.

9. Huang Y, Duan X, Wei Q and Lieber C M, Science, 2001, 291, 630-633.

10. Huang M H, Mao S, Feick H, Yan H Q, Wu Y Y, Kind H, Weber E, Russo R and Yang P D, Science, 2001, 292, 1897.

11. Liu J, Gao P, Mai W, Lao C and Wang Z L, Appl Phys Lett., 2006, 89, 063125.

12. Jaffe B, Cook W R and Jaff H, Piezoelectric Ceramics, Academic Press, NY, 1971, 148.

13. Croker D, Loan M and Hodnett B K, Cryst Growth Des., 2009, 9(5), 2207-2213.

14. Wang X S, Xu C N, Yamada H, Nishikubo K and Zheng X G, Adv Mater., 2005, 17, 1254.

15. Inoue M, Rodriguez A P, Takagi T, Katase N, Kubota M, Nagai N, Nagatsuka H, Nagaoka N, Takagi S, Suzuki K, J Biomater Appl., 2010, 24(7), 657-672.

16. Ringwood A E, Min Mag., 1985, 49, 159-176.

17. Parlinski K, Kawazoe Y and Waseda Y, J Chem Phys., 2001, 114, 2395.

18. Kalendová A, Veselý D and Kalenda P, J Pigment Resin Technol., 2007, 36(3), 123-133.

19. Koper O, Lagadic I and Klabunde K, J Chem Mater., 1997, 9, 838-848.

20. Klabunde K J, Stark J V, Koper O, Mohs C, Park D G, Decker S, Jiang Y, Lagadic I and Zhang D J, Phy Chem., 1996, 100, 12142-12153.

21. Sharma H K and Kapoor P N, Polyhedron, 1988, 7, 1389.

22. Kumar R, J Chem.., 2012, 9(3), 1058-1063. 
23. Kumar R and Sharma H K, J Korean Chem Soc., 2012, 56(1), 54.

24. Sharma H K and Kumar R, Indian J Chem., 2008, 47A, 854-858.

25. Vogel A I, A Text Book of Quantitative analysis, Eds. Longman: London; 1989.

26. Perrin D D, Armarego W L F and Perrin D R, Purification of Laboratory Chemicals, $2^{\text {nd }}$ Edn., Pergamon Press: New York; 1980.

27. Osipov O A, Minkin Verknovodova V I and Knyazhanskii M I, Zh Neorg Khim., 1967, 12, 1549.

28. Bradley D C, Halim F M A and Wardlaw W, J Chem Soc., 1950, 3450.

29. Nakamoto K, Infrared and Raman Spectra of Inorganic and Coordination Compounds, Eds., John Wiley and Sons: New York; 1986.

30. Brcitmair E and Voelter W, ${ }^{13} \mathrm{C}$ NMR spectroscopy (High Resolution Methods and Application in Organic Chemistry and Biochemistry), VCH: New York; 1990.

31. Mirzaee M, Amini M M, Sadeghi M, Mousavi F Y and Sharbatdaran M, CeramSilikáty., 2005, 49(1), 40-47. 